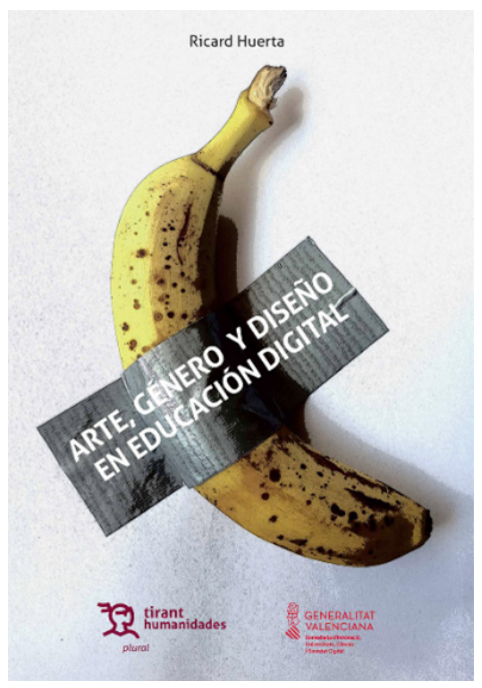

Arte, género y diseño en educación digital

Ricard Huerta

Año: 2020 Lugar:València

Editorial: Tirant Humanidades - Generalitat

Valenciana

Páginas: 327

ISBN: 978-84-18329-13-5

\title{
Educación digital, diseño y género a través del arte
}

El nuevo libro del catedrático de la Universitat de València Ricard Huerta, es el resultado de su compromiso como académico y artista; entre educación, investigación, comunicación de ideas y experiencias sobre creación, arte, género y diseño en educación digital. La publicación cuenta con el apoyo de la Conselleria d'Educació, Cultura i Esport de la Generalitat Valenciana a través del Programa para la promoción de la investigación científica, el desarrollo tecnológico y la innovación a la Comunitat Valenciana, con referencia AORG2019-044, para el Congreso Internacional Humanidades Digitales y Pedagogía Culturales. Además, este trabajo forma parte del proyecto de investigación "Arteari. Arte y diseño para entornos educativos libres de homofobia y transfobia" referencia UV-INV-AE18-779907 de la Convocatoria de Ayudas para Acciones Especiales de Investigación del Vicerrectorado de Investigación de la Universitat de València.

La dilatada experiencia de Ricard Huerta le permite reflexionar desde la educación artística sobre las Humanidades Digitales, las Pedagogías Culturales con su importancia en la enseñanza y el aprendizaje a caballo entre los siglos XX y XXI. Donde la tecnología ha permitido un salto de calidad para transformar la información en conocimiento a través de la educación, cada vez más adaptada a lo digital y con una gran capacidad de proceso y comunicación online. La tecnología está al alcance de una gran parte de las personas, las cuales tienen acceso instantáneo a la información, al mismo tiempo en educación. Los estudiantes disponen de diversos dispositivos que les permiten búsquedas casi sin límites, las cuales pueden asimilar incluso, más rápidamente que los docentes al ser nativos digitales. Esto es definido por Ricard Huerta como tecnoinmersión dentro de la deriva digital en la que nos encontramos, acentuada aún más por la crisis sanitaria actual, donde el modelo online ha potenciado las tecnologías digitales con la inmersión en aplicaciones, servicios y plataformas educativas de gran independencia y velocidad. Las tecnologías 
digitales deben ser aprovechadas por parte de docentes, artistas y profesionales de las humanidades para afrontar la nueva realidad la cultura visual en las que nos encontramos inmersos para poder atender las nuevas reivindicaciones sociales.

A través de siete capítulos, Huerta reflexiona acerca del arte y las humanidades en el universo digital actual, teniendo en consideración cuestiones de género, diseño y educación para afrontar su repercusión en el aprendizaje y la transformación de la imagen como patrimonio colectivo. Lo que como indica el autor, permite el derecho a transitar, en relación con lo educativo o transeducar desde espacios tradicionales en el mundo del arte que toman la red como tema central de sus propuestas o posinternet. Sin olvidar la tecnología de la sexualización, donde los discursos de género son más importantes para la construcción de lo atractivo y deseable que el conocimiento y la práctica sexual. Todas estas reflexiones el autor las desarrolla dentro de cada capítulo en lo que denomina "capsulas de interés", textos breves que concentran una idea a desarrollar por parte de lector en función de su situación personal. Asimismo, son refrendadas mediante las opiniones de artistas y docentes en educación artística recogidas en el libro, sobre las implicaciones de las tecnologías en el hecho artístico y en la instrucción. Considerando diferentes aspectos que repercuten en el aprendizaje, mediante las poéticas de la tecnología, pedagogías inusuales y estéticas comunicativas que parten de experiencias que constatan como nos está transformando el universo digital.

En el primer capítulo comienza con un análisis sobre arte y humanidades en el universo digital, desde la formación en artes del autor, primero como músico en el conservatorio y posteriormente como artista visual en Bellas Artes. Igualmente se desarrolla durante décadas como docente en ambas disciplinas, lo que le permite desde el deleite y conocimiento de las artes valor los beneficios que éstas siempre reportar enmarcadas en el ámbito de la ciudad, entendida esta como lugar de exploración y disfrute de los sentidos. Enfatizada en el momento actual donde se aúnan experiencias reales y virtuales para el desarrollo de las Humanidades Digitales englobadas en lo que se denomina como "macro-área de Arte y Humanidades". Pero a la que Huerta ve con escepticismo por su separación "institucional" de ciencia y tecnología, integrantes de un espacio común de creación. Ligadas al concepto de pasado las primeras y al concepto de futuro las segundas, sensación falsa, no del todo acertada. A estos conceptos el autor aúna otras "capsulas de interés" como la de viajar, la cual le lleva a contemplar la novedad como posibilidad de experiencia y mejora. Concretado en un diseño arriesgado como muestra de dicha acción. En la época en la que nos encontramos de postinternet el viaje puede ser online y la búsqueda de identidades de género, dentro de los actuales cánones de belleza se consigue entender el concepto de educativo desde lo analógico a lo digital, instalados e integrados en la realidad cotidiana. 
En el segundo capítulo, se desarrollan con cierta ironía (Amazon como aliteración y metáfora de Amazonía), las poéticas de la tecnología desde su potencial comunicativo que va más allá de la mera información y se centra en la tecnología digital que permite ampliar una realidad de forma simultánea. La cual ha transformado nuestras vidas a través de la conversión del mundo sensible en bits de información, el autor sostiene que el control de los datos puede suponer una mayor dependencia de quien controla dicha información. Sin embargo, a través del arte y el diseño se pueden desarrollar modelos más porosos y sensibles dentro de la trama del escenario tecnológico actual. Entregado al futuro de las tecnologías y la obsolescencias programadas pero olvidando nuestro necesario desarrollo sostenible. Con este capítulo Huerta, suscita una discusión sobre el empleo de las tecnologías y reflexiona sobre el papel de la sociedad frente el papel de las ingenierías en la educación.

En el capítulo tercero, el autor muestra sus investigaciones sobre tecnologías inusuales o lo que denomina nuevas estéticas comunicativas y estudia su propia experiencia profesional docente. Donde lo digital ya se ha instalado en las docencias offline y online e infiere su pátina digital que nos condiciona en todo momento replanteándonos metodologías y nuestra forma de relacionarnos con profesores y alumnos. El uso responsable de la tecnología es la garantía de poder continuar desarrollando una docencia ética y de calidad, la cual se puede apoyar en las artes tradicionales para generar creaciones pensadas desde lo digital pero en convivencia con lo tradicional. También, la defensa del medioambiente y las cuestiones sociales deben estar presentes en el uso responsable de la tecnología.

El capítulo cuarto se centra en construir la otredad mediante experiencias analógicas y digitales, Huerta parte del concepto de transeducar o derecho a transitar, deconstrucción o construcción de un concepto. A partir de procesos históricos y de acumulaciones metafóricas, disidencias o reconocimiento de la igualdad de derechos para todas las personas y de la experiencia de Museari, (museo online que nació en 2015 y cuyos objetivos principales son la promoción de la educación artística y la historia como instrumentos fundamentales para la defensa de los derechos humanos, incidiendo de modo muy especial en el respeto a la diversidad sexual). En este capítulo se recogen cápsulas de interés de diferentes artistas que colaboran con Museari, como Nora Anacarola, Abel Azcona, Sara Colaone, Maribel Doménech, Alex Flemming, Yolanda Herranz, Mar C. Llop, Álex Meza, Natividad Navalón, Ana Navarrete y Ángel Pantoja, entre otros artistas. Dan vida al proyecto Museari al desarrollar ideas y conceptos en los que predomina la creatividad, la lucha por los derechos humanos de colectivos desfavorecidos, la apuesta por sexualidades y géneros disidentes ante los abusos de poder.

La imagen como patrimonio colectivo es tratada en el capítulo quinto, aquí el autor parte del concepto de cultura visual para dar respuesta a determinados temas ya clásicos. Además introduce la cultura popular dentro del marco académico para poder encuadrar otras culturas en ocasiones menospreciadas, tema a implantar en el 
discurso educativo en relación con los valores humanos y el respecto a la otredad en la búsqueda de equilibrios y porosidades. Algo así sucedió con el cine, el cual en un principio no se incluía junto al resto de las artes, pero sus usos artísticos lo acercaron a otras artes como la pintura y a la música. La reflexión sobre la vida de artistas permite acercarse al proceso de creación para encontrar la verdad, sus obras pueden ser un gran recurso en educación artística. A partir de ellas, se consigue platear un discurso sobre lo artístico, con obras sobre la vida de artistas como Francis Bacon, Jean Michel Basquiat, Joan Brossa, Carmen Calvo, Maurizo Catellan y su obra comediante motivo de la portada de este libro, Gilbert Proesch y George Passmore, David Hockney, Frida Kahlo, Joan Miró, Antoni Tàpies o Andy Warhol. A través de las imágenes de las obras de estos artistas y su acceso mediante la educación digital se consigue transmitir atractivas emociones y posibilidades expresivas.

El sexto capítulo se dedica a las tipografías y al diseño para educar en ciudanía, tema ampliamente desarrollado por el catedrático Ricard Huerta, partiendo de las letras como imagen de la palabra y tecnología al servicio de la escuela para instruir a la población en materia alfabética. Algo parecido a lo que como adultos se vive ante las novedades tecnológicas. En Occidente, la escritura se ha convertido en un medio, pero según el autor, resultaría de gran interés aproximarnos a la caligrafía de las culturas orientales por sus cualidades artísticas. El mundo del diseño consigue plasmar en sus obras aportaciones de género y educción en su universo. Muestra de ello es la opinión de diseñadores como Patricia Bolinches, Marisa Gallén, Roberto Gamonal, Nacho Lavernia, Lucas "Luce”, Javier Mariscal, Vicent Martínez o Iris Richart que parten de la idea del diseño como facilitador de la vida, con ello más libres a las personas y nos ayuda a entender el entorno.

El séptimo y último capítulo recoge la opinión de docentes en educación artística a la pregunta: ¿Cómo nos está transformado el universo digital? Ricard Huerta, considera que actualmente toda la educción es digital, no establece una separación entre educación analógica y educación digital. Cree que es un error considerar la tecnología como un mundo paralelo a la experiencia real, pues la experiencia virtual también es real. En el entorno digital se tiene una concepción del tiempo en la que domina lo instantáneo, arraigado enérgicamente en los jóvenes, aunque no así en otros púbicos más adultos donde el legado temporal cobra mayor importancia. Relacionado con esto se recoge en este capítulo la opinión de especialistas en la materia, sobre cómo está transformado el universo digital la docencia, entre otros: Gabriela Augustowsky, Amparo Alonso-Sanz, María Dolores Arcoba, Martin Cairo, Ricardo Domínguez, Martí Huerta, Germán Navarro-Espinach, Joaquín Paredes, Sidiney Peterson Lima, Ricard Ramon, Rafael Sumozas y Amparo Vilches entre otros.

Como puede apreciarse, este libro aborda diferentes aspectos de la educación digital desde el arte, el género y el diseño. En él se incluyen conceptos, posiciones y perspectivas así como la visión de algunos artistas y docentes recogidas por el autor. 
El libro, totalmente pertinente en el momento actual en el que vivimos, constituye un material de consulta útil para docentes preocupados por la educación digital, desde arte, género y diseño. Esta obra es un magnifico producto educativo, fruto de años de experiencia del artista visual y catedrático de la Universitat de València Ricard Huerta.

Rafael Sumozas. Universidad de Castilla-La Mancha 